\title{
PEMBUATAN GAME FIRST PERSON SHOOTER "FIND ME! SHOOT ME!" DENGAN FITUR SPLIT SCREEN
}

\author{
Dominic Oscar ${ }^{1}$, Jeanny Pragantha ${ }^{2}$, Darius Andana Haris ${ }^{3}$ \\ 1,2,3 Program Studi Teknik Informatika, Fakultas Teknologi Informasi, Universitas \\ Tarumanagara, Jln. Letjen S. Parman No. 1, Jakarta, 11440, Indonesia \\ E-mail:1'dominicoscar12@gmail.com, ${ }^{2}$ jeannyp@fti.untar.ac.id, ${ }^{3}$ dariush@fti.untar.ac.id
}

\begin{abstract}
Abstrak
Game "Find Me! Shoot Me!" adalah game yang ber-genre First Person Shooter dengan fitur split screen dalam satu layar dan invisible character yaitu visual karakter tidak terlihat. Game ini dibuat dengan tujuan memberikan pengalaman bermain game First Person Shooter yang berbeda dari biasanya. Game ini mempunyai tampilan berbentuk tiga dimensi dan dimainkan menggunakan komputer atau laptop berbasis windows dengan alat kontrol joystick controller. Game ini dibuat menggunakan Unity dengan C\# sebagai bahasa pemrograman. Pemain ditugaskan untuk mencari dan membunuh pemain lainnya. Permainan akan berakhir jika salah satu pemain telah mencapai poin yang telah ditentukan. Fitur multiplayer game ini dimainkan minimal dua pemain dan maksimal empat pemain.
\end{abstract}

Kata kunci: Find Me! Shoot Me!, First Person Shooter, Game 3D, Multiplayer, Split Screen, Unity.

\section{Abstract}

Game "Find Me! Shoot Me!" is a game that has First Person Shooter Genre with split screen feature in one screen and invisible character that is visual of the character is not visible. This game was created with the aim of providing a First Person Shooter game experience that is different than usual. This game has a $3 D$ display and played using a windows based computer or laptop and using joystick controller for the control tool.This game was created using Unity with $C \#$ as a programming language. Player are assigned to search and kill other players. The game will end if one the player has reached a predetermined point. This multiplayer game feature is played at least two players and maximum of four players.

Keywords: Find Me! Shoot Me!, First Person Shooter, Game 3D, Multiplayer, Split Screen, Unity.

\section{PENDAHULUAN}

Genre First Person Shooter pada umumnya dimainkan oleh satu pemain secara full screen dalam satu layar dan tentunya dapat melihat secara visual karakter pemain lainnya. Contoh tampilan game yang memiliki genre yang sejenis dan telah dibuat adalah "Synodeia" yang dibuat oleh William Darma Saputra [1]. Game "Find Me! Shoot Me!" merupakan game ber-genre First Person Shooter dengan fitur multiplayer split screen. Pada game ini, pemain diharuskan untuk mencari dengan cara melihat layar pemain lainnya dan membunuh pemain lainnya, pemain yang membunuh pemain lainnya akan mendapatkan satu poin. Permainan akan berakhir jika salah satu pemain telah mencapai poin yang telah ditentukan yaitu tujuh poin. 


\section{DASAR TEORI}

Dalam melakukan perancangan suatu game tentu diperlukan dasar-dasar teori yang digunakan dalam membuat game tersebut agar game menjadi bagus dan sesuai dengan yang diinginkan. Beberapa dasar teori yang mendukung pembuatan game ini yang akan dijelaskan antara lain genre game dan collision detection.

\subsection{Genre Game}

Genre merupakan sebuah peranan penting dalam sebuah game. Genre menggambarkan tentang tema, alur sebuah game secara garis besar. Terdapat lebih dari satu genre yang sudah ada sekarang ini. Beberapa genre game yaitu sebagai berikut [2]:

1. Action

Action game merupakan game yang menyediakan beberapa rintangan dan musuh yang harus dikalahkan oleh pemain dengan menggunakan reaksi cepat dan terkadang tidak memberikan banyak teka-teki pada pemain.

2. Fighting

Fighting game merupakan game yang mensimulasikan pertarungan dengan satu musuh atau lebih. Pada umumnya genre ini melibatkan kekerasan, dan juga terkadang musuh bukan manusia melainkan makhluk yang tidak masuk akal.

3. Strategy

Strategy game biasanya mengajak pemain untuk memikirkan strategi atau cara untuk menyelesaikan masalah maupun untuk mendapatkan kemenangan. Genre ini lebih cenderung logistical challenges yang sering kali membuat kesal pemainnya karena terlalu sulit.

4. Role-Playing Game (RPG)

Role-playing games merupakan game yang memiliki gameplay yang mengandung unsur leveling. Game ini mengharapkan pemain untuk mengikuti alur cerita, tetapi tidak menutup kemungkinan pemain dapat bebas menjelajah dari dunia game. Biasanya pemain diberikan satu karakter yang memiliki kemampuan dan kekuatan yang berbeda-beda. Genre ini memiliki karakteristik competitive dan bahkan dapat berinteraksi dengan pemain lain.

5. Simulation

Genre ini merupakan simulasi dari keadaan nyata. Pemain diajak untuk merasakan langsung kejadian di lingkungan yang diinginkan tanpa melibatkan aktifitas yang asli, seperti membangun simulasi sebuah kota, negara atau koloni. Bahkan permainan simulasi ini banyak digunakan untuk pengetahuan seperti melakukan pembedahan.

6. Adventure

Adventure games yaitu game petualangan. Pemain akan menemukan banyak hal dan peralatan yang akan membantu dalam game tersebut. Peralatan ini bisa digunakan menjadi petunjuk bahkan menjadi jebakan. Biasanya game ini memiliki conceptual challenges yang akan membuat pusing pemain.

7. Puzzle

Puzzle games yang selalu memberikan tantangan kepada pemain dengan cara menjatuhkan sesuatu dari segala sisi. Pemain harus menyusun sedemikian rupa sehingga tidak ada yang tersisa. Susunan ini dilakukan secepat mungkin, karena semakin lama akan semakin cepat dan banyak objek yang jatuh.

8. Shooter

Shooter games tentunya adalah salah satu genre yang paling sering dimainkan oleh para pencinta game. Genre ini memiliki tema dasar peperangan pada alur ceritanya dengan menggunakan senjata api dan benda tajam. Shooter game juga dapat dibagi menjadi beberapa sub-genre berdasarkan sudut pandang: 
a. Third Person Shooters (TPS)

Third person shooter adalah game shooter yang mensimulasikan pemain menggunakan sudut pandang orang ketiga. Sudut pandang ini memperlihatkan seluruh bentuk tubuh dari karakter pemain yang digunakan (Contoh: Star Wars II: Battlefront)

b. First Person Shooter (FPS)

First person shooter adalah game shooter yang paling sering ditemukan karena. Subgenre ini mensimulasikan sudut pandang pertama. Sudut pandang ini mensimulasikan bahwa kita menjadi karakter permainan tersebut secara langsung. Beberapa game yang menggunakan sudut pandang ini adalah Counter Strike: Global Offensive, Point Blank, Cross Fire. Tampilan First Person Shooter dapat dilihat pada Gambar 1.

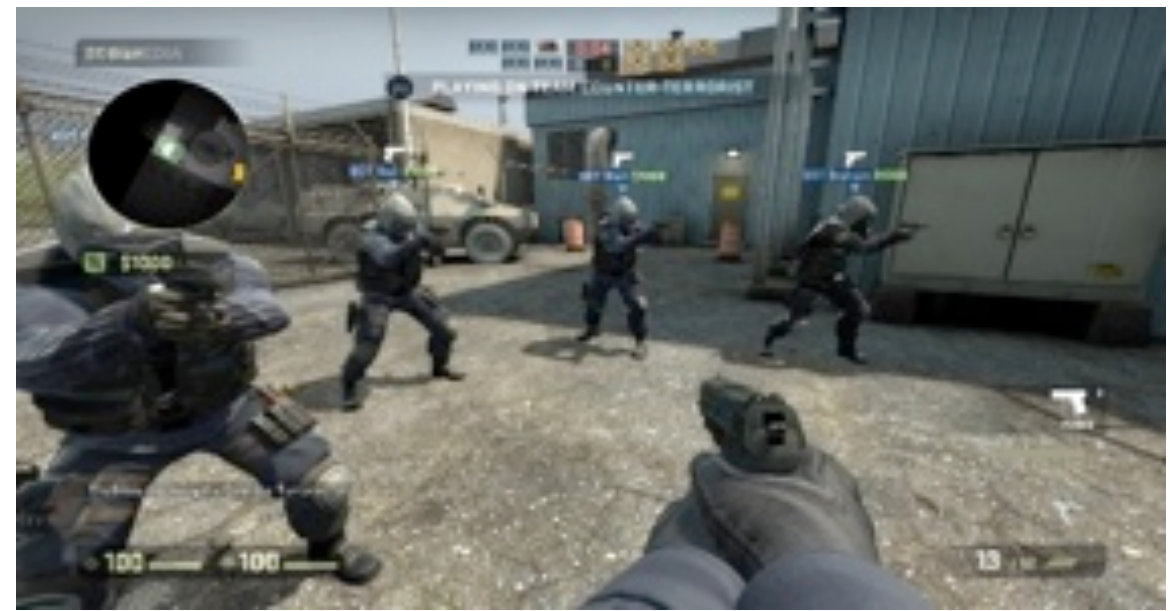

Gambar 1 Tampilan Game Counter Strike: Global Offensive

c. Shooting Gallery

Sub-genre ini biasanya dapat menggunakan joypad dan on-screen cursor untuk mengarahkan kearah mana senjata akan ditembakkan (Contoh: Time Crisis).

d. Tactical Shooter

Tactical shooter merupakan game shooter yang memiliki tema peperangan berbasis squad atau man-to-man skirmish. (Contoh: Ghost Recon).

e. Hero Shooter

Hero shooter menawarkan gameplay yang terkesan lebih mengutamakan kesenangan bermain dibandingkan adu skill dan koordinasi tim seperti layaknya game shooter kompetitif biasa. Hal ini juga didorong oleh perilaku pemain yang sering kali memilih mode casual dibandingkan mode competitive seperti ranked match pada Counter Strike: Global Offensive. Itulah sebab hero shooter semakin identik dengan kesenangan bermain shooter game semata (Contoh: Overwatch).

f. Multiplayer Party

Game multiplayer party merupakan jenis permainan yang dapat dimainkan lebih dari satu pemain pada arena game yang sama dan pada waktu yang bersamaan. Setiap pemain dalam game multiplayer memungkinkan setiap pemainnya saling berinteraksi dengan pemain lainnya, bekerja sama dalam tim yang sama, menjadi lawan tanding dan hingga mampu menyediakan bentuk komunikasi sosial yang hampir tidak ditemukan pada game dengan orientasi single player. Game multiplayer ini bisa bersifat online maupun offline (Contoh: Mario Party).

Game "Find Me! Shoot Me!" yang dirancang merupakan game ber-genre First Person Shooter digabungkan dengan multiplayer party. 


\subsection{Collision Detection}

Metode ini digunakan untuk melakukan pengecekan suatu kondisi saat objek-objek saling berkenaan atau bertabrakan. Unity telah menyediakan komponen yang bernama collider yang dapat digunakan pada objek yang diinginkan. Collision detection menginformasikan bahwa jika setiap collider ada yang saling bertabrakan, maka Unity akan mensimulasikan reaksi tergantung dari pengaturan yang telah ditentukan oleh pengembang game. Contoh yang terlihat realistis adalah pada saat satu objek berupa orang yang bertabrakan dengan objek lain berupa peluru senjata tentunya akan terjadi physical simulation yang akan membantu mensimulasi efek orang tertembak [3]. Gambar dapat dilihat pada Gambar 2.

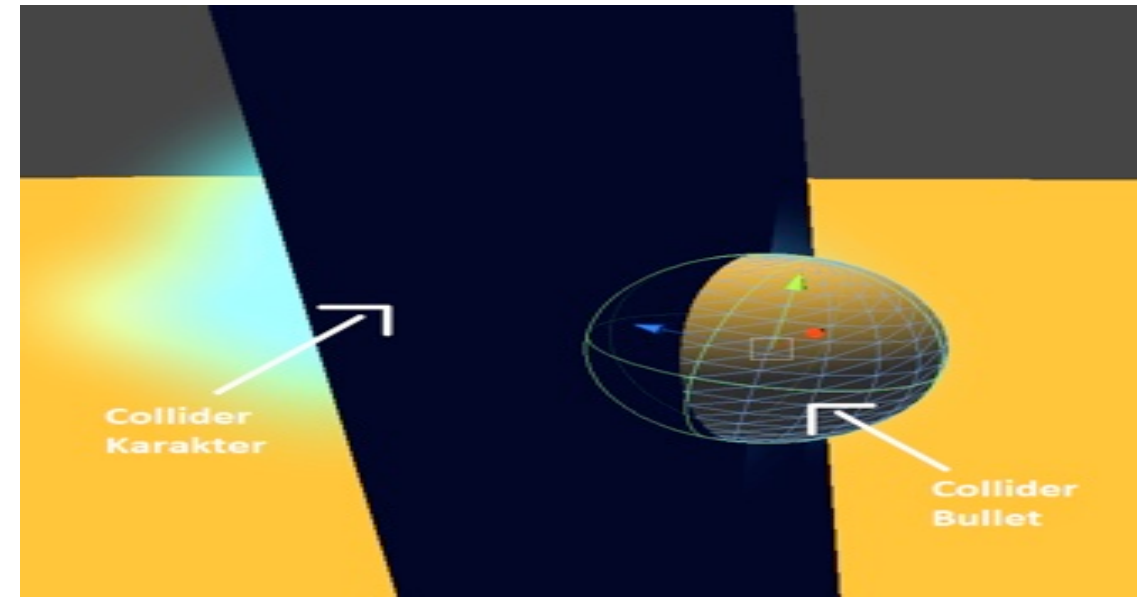

Gambar 2 Simulasi Collision Detection

\section{PERANCANGAN}

\subsection{Gameplay}

Gameplay dari game "Find Me! Shoot Me!" sederhana dan tidak menggunakan kontrol yang rumit sehingga mudah dimainkan, berikut ini adalah perancangan gameplay dari game "Find Me! Shoot Me":

1. Terdapat 5 pilihan pada menu utama permainan yaitu "Play", "Option", "About", "Help" dan "Exit". Rancangan Menu Utama dapat dilihat pada Gambar 3.

\section{Find Me! Shoot Me!}
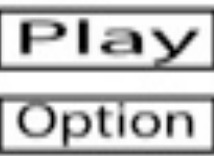

About

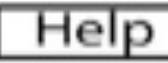

\section{Exit}

Gambar 3 Rancangan Desain Menu Utama 
2. Pada tengah layar terdapat crosshair dan pemain harus mengarahkannya ke arah target dengan menggerakkan mouse untuk menembak monster. Rancangan tampilan layar pada game "Find Me! Shoot Me!" dapat dilihat pada Gambar 4.

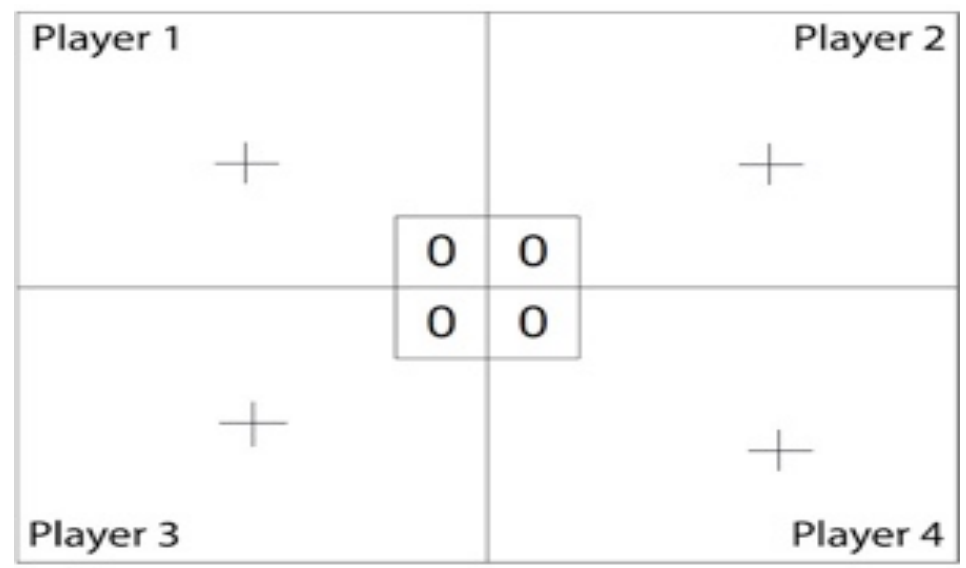

Gambar 4 Rancangan Tampilan Layar Game "Find Me! Shoot Me!"

3. Pemain dapat menggerakan karakter dengan menggunakan joystick controller untuk berjalan, melompat, mengganti senjata dan menembakkan senjata. Rancangan skema joystick controller dapat dilihat pada Gambar 5.

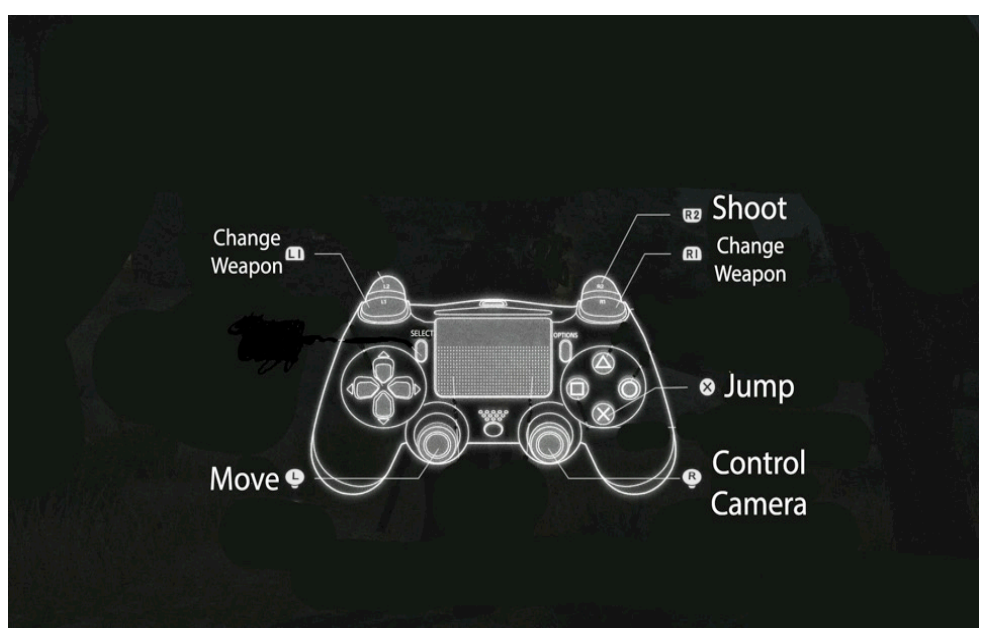

Gambar 5 Rancangan Skema Joystick Controller

4. Pemain dapat menggunakan salah 1 dari 4 jenis senjata dengan peluru tidak terbatas. Masing-masing senjata memiliki karakteristik senjata yang berbeda. Terdapat 3 senjata ranged dan 1 senjata melee.

5. Pemain harus mencari dan membunuh pemain lainnya agar mendapatkan poin.

6. Permainan berakhir jika salah satu pemain telah mencapai poin yang telah ditentukan.

\subsection{Implementasi}

Rancangan yang telah dibuat telah diimplementasikan dengan menggunakan Unity3D. Sebagai langkah awal, diimplementasikan pergerakan karakter. Untuk itu, digunakan objek kapsul sebagai pengganti karakter dan balok sebagai senjata. Pada objek kapsul diberikan script First Person Controller Script yang digunakan untuk menggerakkan kapsul, script Player 
Shooting yang digunakan untuk menembak, serta beberapa script lain yang dibutuhkan untuk melakukan aktivitas lain seperti serangan jarak dekat (melee) dan lainnya. Tampilan objek kapsul dapat dilihat pada Gambar 6.

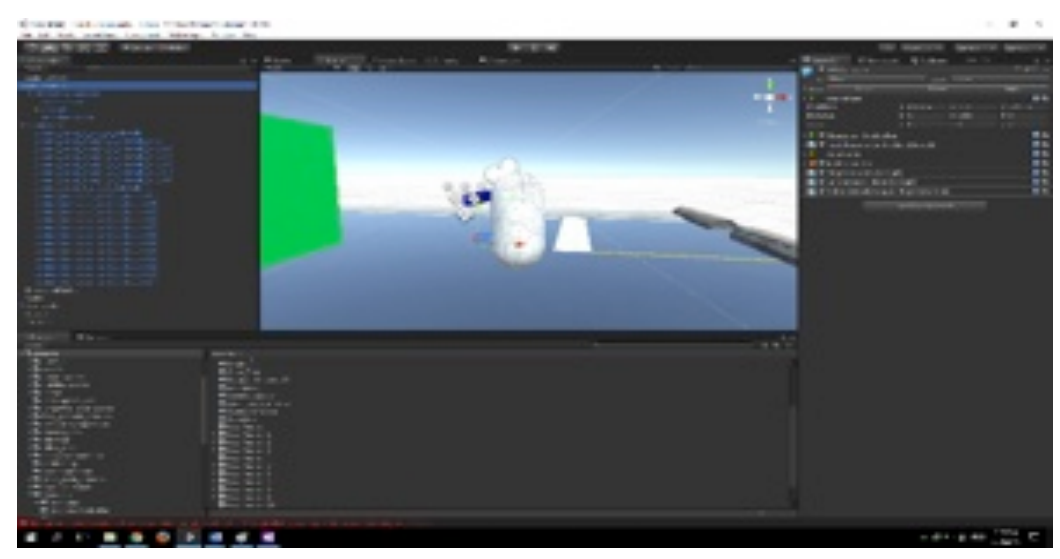

Gambar 6 Objek Sementara Karakter

Selanjutnya, rancangan map diimplementasikan dengan Unity3D. Hasilnya dapat dilihat pada Gambar 7.

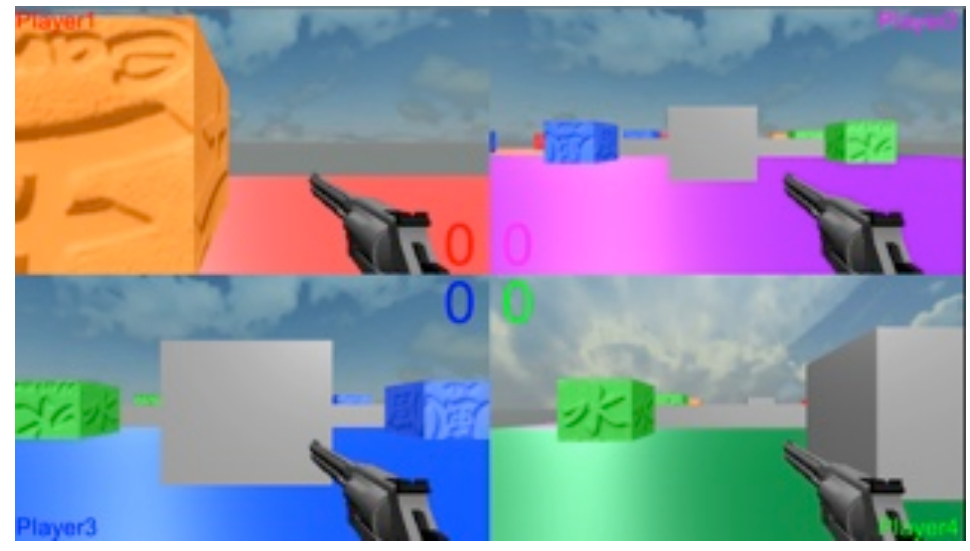

Gambar 7 Tampilan 4 Pemain

Selanjutnya objek karakter yang terkena tembakan dapat dikondisikan dengan menambahkan script saat collision detection pada collider karakter. Tampilan saat tertembak dapat dilihat pada Gambar 8.

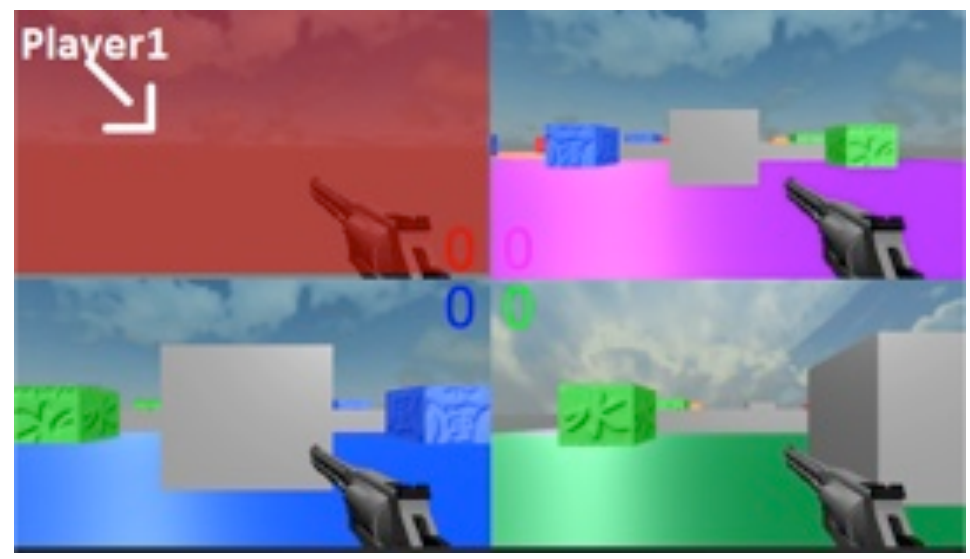

Gambar 8 Tampilan Player1 Die 


\section{PENGUJIAN RANCANGAN}

Pengujian dilakukan pada hasil implementasi rancangan dengan menjalankan semua fitur yang ada seperti:

1. Karakter dapat bergerak maju, mundur, ke kiri, ke kanan dan melompat. Karakter juga dapat menembak, mengganti senjata dan melakukan serangan jarak dekat.

2. Kontrol joystick dapat digunakan secara individual untuk menggerakkan masing-masing karakter.

3. Tampilan layar pemain telah dibagi sesuai dengan banyaknya pemain yang bermain.

4. Pemain yang tertembak tidak dapat bergerak selama 2 detik.

5. Pemain yang tertembak akan hidup kembali dengan random respawn point setelah menunggu selama 2 detik.

6. Text box score point dapat menampilkan poin masing-masing pemain dan angkanya bertambah jika membunuh pemain lainnya.

7. Text box win akan muncul jika salah satu pemain telah mencapai poin yang ditentukan. Tampilan win dapat dilihat pada Gambar 9.

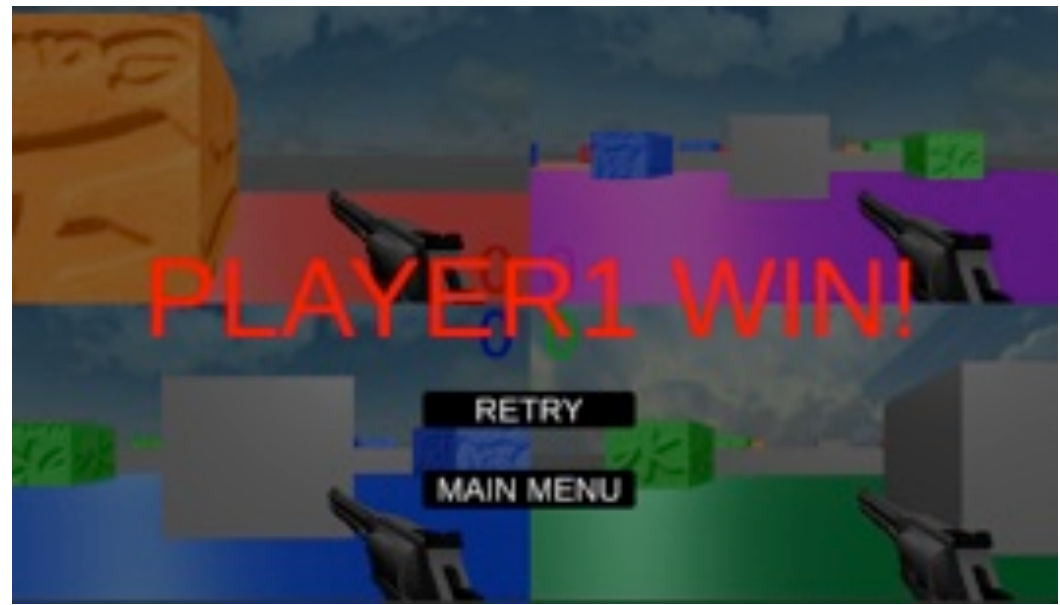

Gambar 9 Tampilan Player1 Win

8. Semua modul pada menu utama dapat digunakan sesuai dengan fungsinya.

Setelah seluruh pengujian selesai dilakukan, hasil pengujian kemudian dikumpulkan dan dibahas untuk memeriksa hasil dari pengujian tersebut. Berikut ini adalah hasil pengujian beta testing dari tiga puluh responden:

1. Sebanyak $70 \%$ responden menyatakan pernah bermain permainan ber-genre serupa.

2. Sebanyak $73 \%$ responden menyatakan pernah memainkan permainan dengan fitur multiplayer split screen.

3. Sebanyak $63 \%$ responden menyatakan bahwa tidak kesulitan dengan kontrol permainan "Find Me! Shoot Me!".

4. Hanya $33 \%$ responden lebih memilih bermain multiplayer secara split screen dalam satu layar.

5. Sebanyak $77 \%$ responden menjawab tampilan grafis permainan cukup dan $23 \%$ responden menyatakan tampilan grafis baik.

6. Sebanyak 97\% responden menyatakan permainan "Find Me! Shoot Me!" cukup menghibur.

7. Sebanyak $100 \%$ responden menyatakan tertarik untuk bermain lagi. 


\section{KESIMPULAN}

Dari hasil pengujuan, permainan "Find Me! Shoot Me!" memiliki gameplay yang sederhana tetapi menarik sehingga pemain tertarik untuk bermain lagi. Untuk fitur multiplayer split screen yang diterapkan dalam permainan ini sudah berjalan cukup baik. Game "Find Me! Shoot Me!" ini dapat memberikan hiburan yang cukup pada pemain. Pemain merasa terhibur meskipun belum pernah memainkan game serupa. Kontrol game "Find Me! Shoot Me!" lebih mudah untuk dimainkan menggunakan Xbox 360 Controller. Secara keseluruhan kontrol sudah cukup baik.

\section{UCAPAN TERIMA KASIH}

Penulis mengucapkan terima kasih yang sebesar-besarnya kepada Prof. Dr. Dyah Erny H, M. Si dan Bagus Mulyawan, S.Kom., MM yang telah memberi masukan terhadap pembuatan game ini.

\section{DAFTAR PUSTAKA}

[1] William Darma. 2017. Pembuatan Game Co-Op Survival First Person Shooter "Synodeia". Jakarta: Jurnal Ilmu Komputer dan Sistem Informasi. Vol. 5.No. 1:203-209.

[2] Ernest Adams, Fundamentals of Game Design, (Berkeley: New Riders, 2010), h. 69.

[3] Christer Ericson, Real Time Collision Detection, (Boca Raton: CRC Press, 2004), h. 1214. 